NASA/TM-2000-210356

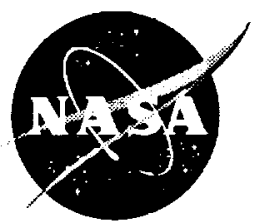

Flying Qualities Evaluation of a Commuter Aircraft With an Ice Contaminated Tailplane

Richard J. Ranaudo

Bombardier Aerospace, Wichita, Kansas

Thomas P. Ratvasky

Glenn Research Center, Cleveland, Ohio

Judith Foss Van Zante

Dynacs Engineering Company, Inc. Brook Park, Ohio 
Since its founding, NASA has been dedicated to the advancement of aeronautics and space science. The NASA Scientific and Technical Information (STI) Program Office plays a key part in helping NASA maintain this important role.

The NASA STI Program Office is operated by Langley Research Center, the Lead Center for NASA's scientific and technical information. The NASA STI Program Office provides access to the NASA STI Database, the largest collection of aeronautical and space science STI in the world. The Program Office is also NASA's institutional mechanism for disseminating the results of its research and development activities. These results are published by NASA in the NASA STI Report Series, which includes the following report types:

- TECHNICAL PUBLICATION. Reports of completed research or a major significant phase of research that present the results of NASA programs and include extensive data or theoretical analysis. Includes compilations of significant scientific and technical data and information deemed to be of continuing reference value. NASA's counterpart of peerreviewed formal professional papers but has less stringent limitations on manuscript length and extent of graphic presentations.

- TECHNICAL MEMORANDUM. Scientific and technical findings that are preliminary or of specialized interest, e.g., quick release reports, working papers, and bibliographies that contain minimal annotation. Does not contain extensive analysis.

- CONTRACTOR REPORT. Scientific and technical findings by NASA-sponsored contractors and grantees.
- CONFERENCE PUBLICATION. Collected papers from scientific and technical conferences, symposia, seminars, or other meetings sponsored or cosponsored by NASA.

- SPECIAL PUBLICATION. Scientific, technical, or historical information from NASA programs, projects, and missions, often concerned with subjects having substantial public interest.

- TECHNICAL TRANSLATION. Englishlanguage translations of foreign scientific and technical material pertinent to NASA's mission.

Specialized services that complement the STI Program Office's diverse offerings include creating custom thesauri, building customized data bases, organizing and publishing research results ... even providing videos.

For more information about the NASA STI Program Office, see the following:

- Access the NASA STI Program Home Page at http://www.sti.nasa.gov

- E-mail your question via the Internet to help@sti.nasa.gov

- Fax your question to the NASA Access Help Desk at (301) 621-0134

- Telephone the NASA Access Help Desk at (301) 621-0390

- Write to:

NASA Access Help Desk

NASA Center for AeroSpace Information 7121 Standard Drive

Hanover, MD 21076 
NASA/TM-2000-210356

SAE 2000-01-1676

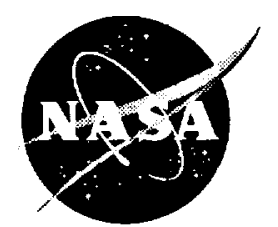

\section{Flying Qualities Evaluation of a Commuter Aircraft With an Ice Contaminated Tailplane}

Richard J. Ranaudo

Bombardier Aerospace, Wichita, Kansas

Thomas P. Ratvasky

Glenn Research Center, Cleveland, Ohio

Judith Foss Van Zante

Dynacs Engineering Company, Inc. Brook Park, Ohio

Prepared for the

General Aviation Technology Conference and Exposition (GATC)

sponsored by the Society of Automotive Engineers

Wichita, Kansas, May 9-11, 2000

National Aeronautics and

Space Administration

Glenn Research Center 


\section{Acknowledgments}

The authors wish to thank the participating organizations and guest pilots from the FAA, Transport Canada, Cessna, Raytheon, Bombardier-Learjet for pilot support and participation. We also would like to thank the sponsors of the NASA/FAA TIP: the NASA Aerospace Operations Systems base program and the FAA William J. Hughes Technical Center.

Trade names or manufacturers' names are used in this report for identification only. This usage does not constitute an official endorsement, either expressed or implied, by the National

Aeronautics and Space Administration.

Available from

NASA Center for Aerospace Information 7121 Standard Drive Hanover, MD 21076

Price Code: A03
National Technical Information Service 5285 Port Royal Road Springfield, VA 22100

Price Code: A03 


\title{
Flying Qualities Evaluation of a Commuter Aircraft With an Ice Contaminated Tailplane
}

\author{
Richard J. Ranaudo \\ Bombardier Aerospace \\ Wichita, Kansas \\ Thomas P. Ratvasky \\ National Aeronautics and Space Administration \\ Glenn Research Center \\ Cleveland, Ohio 44135 \\ Judith Foss Van Zante \\ Dynacs Engineering Company, Inc. \\ Brook Park, Ohio 44142
}

\begin{abstract}
During the NASA/FAA Tailplane Icing Program, pilot evaluations of aircraft flying qualities were conducted with various ice shapes attached to the horizontal tailplane of the NASA Twin Otter lcing Research Aircraft. Initially, only NASA pilots conducted these evaluations, assessing the differences in longitudinal flight characteristics between the baseline or clean aircraft, and the aircraft configured with an Ice Contaminated Tailplane (ICT). Longitudinal tests included Constant Airspeed Flap Transitions. Constant Airspeed Thrust Transitions, zero-G Pushovers, Repeat Elevator Doublets, and, Simulated Approach and Go-Around tasks. Later in the program, guest pilots from government and industry were invited to fly the NASA Twin Otter configured with a single full-span artificial ice shape attached to the leading edge of the horizontal tailplane. This shape represented ice formed due to a "Failed Boot" condition. and was generated from tests in the Glenn Icing Research Tunnel on a full-scale tailplane model. Guest pilots performed longitudinal handling tests, similar to those conducted by the NASA pilots, to evaluate the ICT condition In general, all pilots agreed that longitudinal flying qualities were degraded as flaps were lowered, and further degraded at high thrust settings. Repeat elevator doublets demonstrated reduced pitch damping effects due to ICT, which is a characteristic that results in degraded flying qualities. Pilots identified elevator control force reversals (CFR) in zero-G pushovers at a $20^{\circ}$ flap setting, a characteristic that fails the FAR 25 no CFR certification requirement. However, when the same pilots used the Cooper-Harper rating scale to perform a simulated approach and goaround task at the $20^{2}$ flap setting, they rated the airplane as having Level I and Level II flying qualities
\end{abstract}

respectively. By comparison, the same task conducted at the $30^{\circ}$ flap setting, resulted in Level II flying qualities for the approach portion, and Level III for the go-around portion.

The results of this program indicate that safe and acceptable flying qualities with an ICT condition, can be effectively assessed by task-oriented pilot maneuvers. In addition, other maneuvers such as repeat elevator doublets provide good qualitative and quantitative assessments of pitch damping and elevator effectiveness, which are characteristics that correlate well with pilot task ratings. The results of this testing indicate that the FAR 25 zero-G pushover maneuver, which requires no CFR during its execution, may be an overly conservative pass/fail criteria for aircraft certification.

\section{INTRODUCTION}

Aircraft accident analyses have revealed ice contamination on horizontal tailplanes as the primary cause of 16 accidents resulting in 139 fatalities'. Ice can lead to a premature tail stall that causes the aircraft to pitch nose-down, which at low altitude may not be recoverable prior to impact with the ground. Three International Tailplane Icing Workshops were convened to appraise the collective experience on icecontaminated tailplane stall (ICTS) from airframe manufacturers, operators, aviation regulators, and other interested parties. Workshop attendees provided recommendations to reduce the number of accidents attributed to ICTS. In response to some of these recommendations, the Federal Aviation Administration (FAA) requested the National Aeronautics and Space Administration (NASA) to conduct research into the characteristics of ice-contaminated tailplane stall and to 
develop techniques and methodologies to minimize the hazard.

NASA developed the NASA/FAA Tailplane Icing Program (TIP), a four-year research effort utilizing a combination of icing experts and test facilities. These included the NASA Glenn (formerly NASA Lewis) Icing Research Tunnel (IRT), The Ohio State University (OSU) Low Speed Wind Tunnel, and the NASA Glenn DeHavilland DHC-6 Twin Otter lcing Research Aircraft ${ }^{2}$. The TIP succeeded in: 1) improving the state of knowledge of iced tailplane aeroperformance and aircraft aerodynamics $^{3,4,5,6,87}, 2$ ) developing analytical tools to help discriminate tailplane sensitivity to icing ${ }^{8,9}$, and 3 ) producing training aids to expand the awareness of the ICTS aviation hazard ${ }^{10,11 .}$

Although much of the TIP data has been reported, the flying qualities aspect of an ice-contaminated tailplane (ICT) has not been fully discussed. Therefore, the purpose of this report is to present NASA's findings on the longitudinal flying qualities of an ICT. The report is organized in the following sections: description of the research aircraft, instrumentation systems, ice shape used, flight test procedures, results of the evaluation, and conclusions drawn from the effort.

\section{RESEARCH AIRCRAFT}

The NASA lcing Research Aircraft - N607NA (Figure 1) is a modified DeHavilland DHC-6 Twin Otter. It is powered by two 550 SHP Pratt and Whitney PT6A-20A turbine engines driving three-bladed Hartzell constant speed propellers. The flight controls are mechanically operated through a system of cables and pulleys. Control surfaces consist of elevator, ailerons, rudder, and wing flaps. The horizontal tailplane has a fixed stabilizer with an elevator and trim tab.

\section{INSTRUMENTATION SYSTEMS}

The research data acquisition systems enabled measurements of the 1) aircraft dynamics, 2) tailplane aeroperformance, and 3) tailplane flow visualization and pilot visual and tactile cues. The aircraft dynamics data set included: inertial data, air data, control surface deflection data, pilot forces, and engine parameter data. The tailplane aeroperformance data set consisted of three 5-hole flow probes to measure tail inflow angles and velocities and a pressure belt wrapped chordwise around the stabilizer and elevator to measure surface pressures (Figure 2).
Flow visualization on the tailplane was accomplished by mounting a video camera to the bottom aft section of the fuselage with a field-of-view of the lower left-hand horizontal tail. Yarn tufts were attached in a matrix of spanwise and chordwise positions to visualize the flow separation and reattachment in various zones on the tailplane.

Another unique video system was installed to record the pilot actions during the maneuvers and also record the view through the windscreen to obtain the pilots perspective. These two views were merged onto a single screen format by using a screen splitter so that the upper part of the screen showed the view through the windscreen, while the lower part of the screen presented an over-the-shoulder look at the pilot controlling the aircraft. This single screen presentation was annotated with engineering unit data to indicate the aircraft pitch and roll angles, pilot forces, thrust coefficient and elevator angle. This video signal was then recorded in SVHS format with an audio record of the intercom comments made by the pilots and engineers.

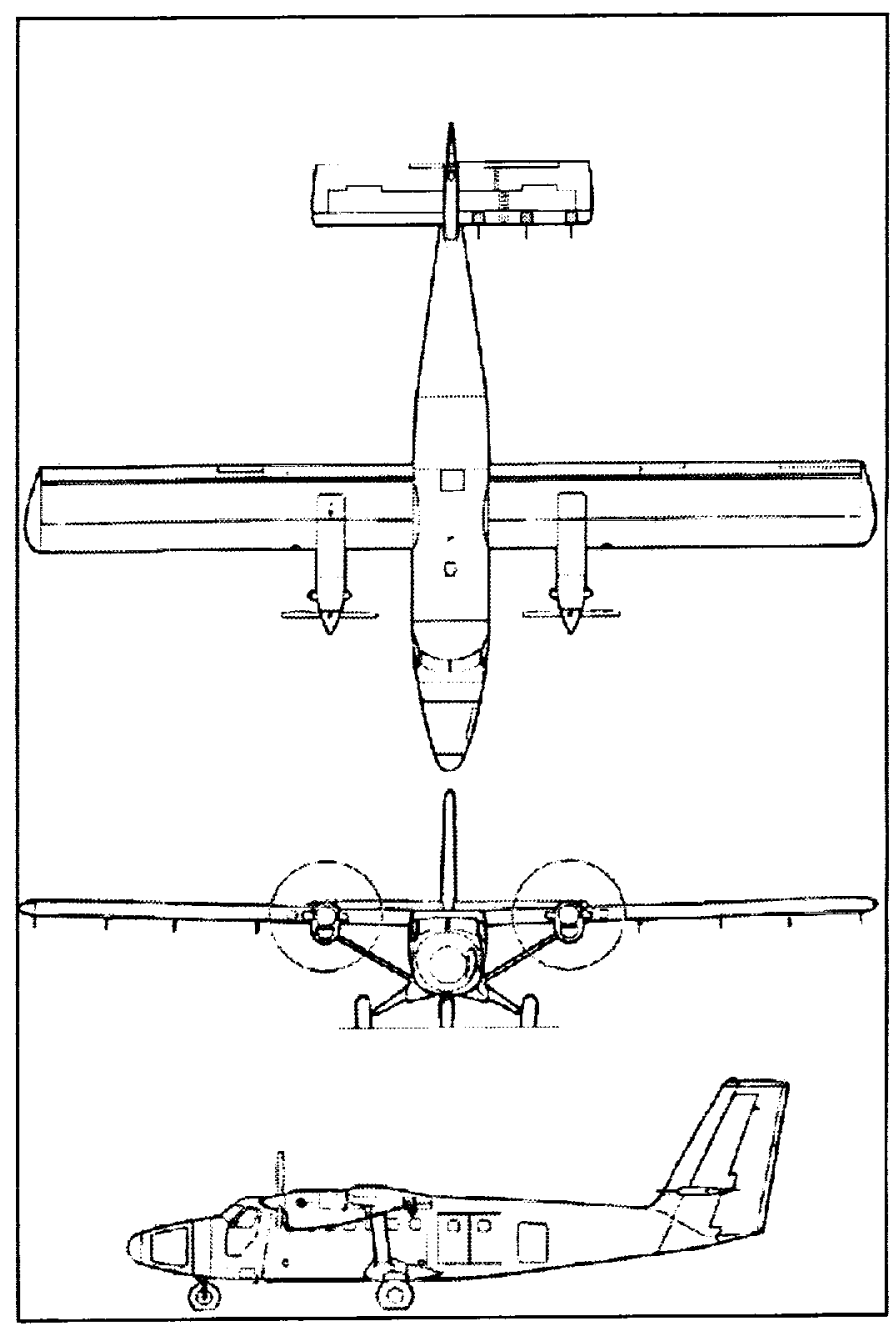

Figure 1. NASA Glenn lcing Research Aircraft 


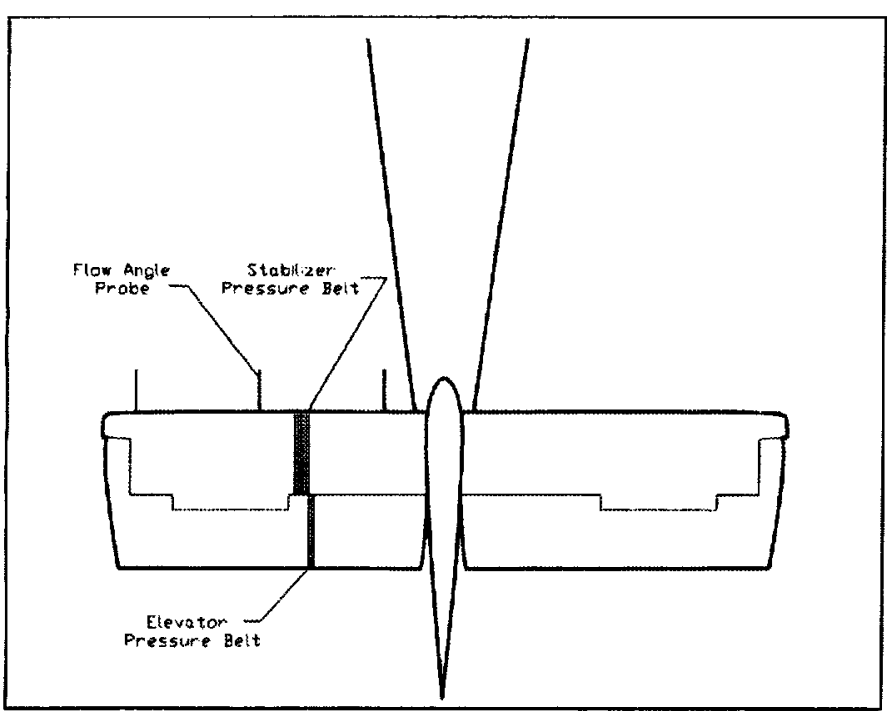

Figure 2. Flow probe and pressure belt layout

\section{ICE CONTAMINATION}

Within the context of this report, the NASA Twin Otter was tested with an ice shape that represented a Failed Boot ice accretion (Figure 3). The Failed Boot shape resulted from a NASA lcing Research Tunnel (IRT) test on a full-scale Twin Otter tailplane model using FAR 25 Appendix C conditions. A mold of the IRT ice accretion was made; from which urethane casts were formed. These casts retained the overall shape and rough texture of the actual ice accretion. Multiple casts of the Failed Boot lce were made to cover the entire span of the horizontal stabilizer's leading edge. No other surfaces were contaminated.

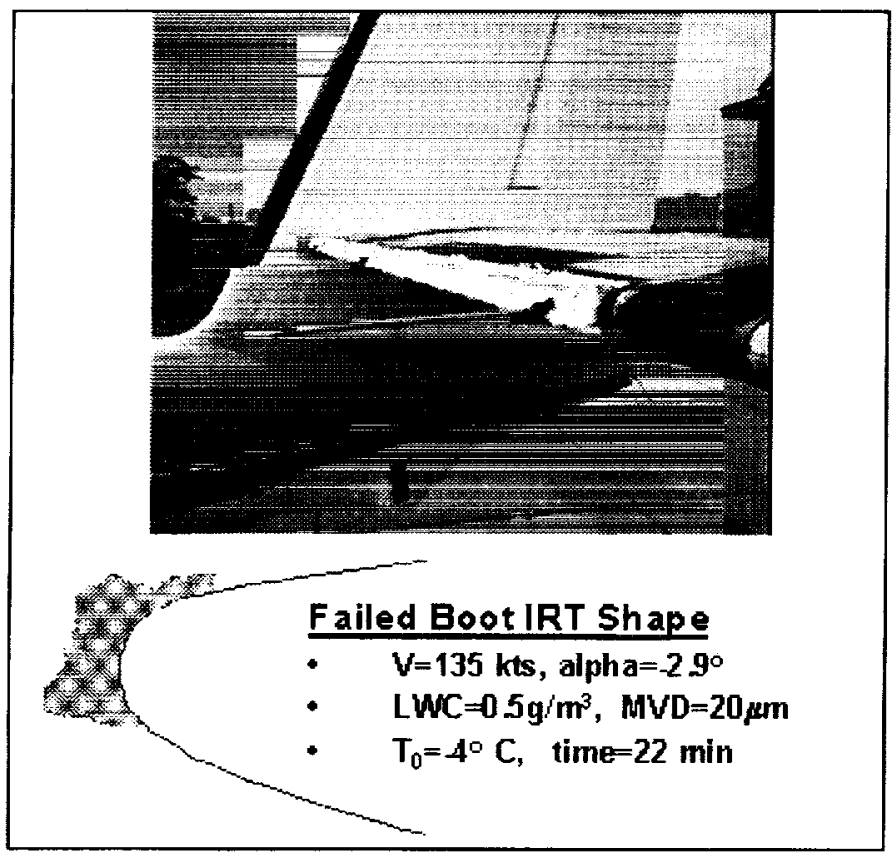

Figure 3. Failed Boot Ice Shape

\section{FLIGHT TEST PROCEDURES}

The flight test maneuvers selected for this program were developed to acquire tailplane aerodynamic data for the TIP program, and to provide pilot evaluation scenarios for assessing the effects of the ICT condition on airplane flying qualities. Quasi-steady maneuvers, which included Flap Transitions, and Thrust Transitions, were used to isolate configuration and power effects on longitudinal stability and control. Dynamic maneuvers included; a.) the zero-G pushover, to demonstrate a CFR condition and the effects of pilot technique on CFR tactile cues; and, b.) repeat elevator doublets, to demonstrate ICT effects on longitudinal pitch damping and elevator effectiveness. Lastly, an approach and go-around pilot evaluation task was flown with a $20^{\circ}$ and a $30^{\circ}$ flap setting. The Cooper-Harper ${ }^{12}$ pilot rating scale was used to rate the approach and go-around tasks for each flap setting. This test allowed pilots to evaluate the effects of increasing flap angles on longitudinal flying qualities in a structured manner. During the course of this particular exercise, pilots were also asked to associate their ratings for the $20^{\circ}$ flap cases with the observations they made while conducting the zero-G pushover maneuver in the same configuration. This provided an opportunity to compare results from a closed loop task (approach and go-around), and an open loop task (zero-G pushover) in assessing acceptable flying qualities. A description of each of the flight test maneuvers follows:

Flap Transitions (Figure 4-Figure 5) were flown to evaluate the effect of flap position on longitudinal trim and control characteristics. The aircraft was initially trimmed at $85 \mathrm{KIAS}$ with the flaps up, and a thrust setting equivalent to $a C_{T}=0.10$. Flaps were then lowered from $0^{\circ}$ to $40^{\circ}$. Trim speed was maintained without changing engine thrust setting or longitudinal trim setting, while noting the effect of increasing flap angle on stick force characteristics. The results reported herein are from NASA in house testing, and illustrate a comparison between the clean and contaminated tail for the same maneuver.

Constant airspeed thrust transitions (Figure 6) were flown to evaluate the effect of thrust on longitudinal trim and elevator control force characteristics. The example provided in this report shows a thrust transition that eventually resulted in a tail stall. Here, the aircraft was configured with the Failed Boot ice shape, and initially trimmed at $85 \mathrm{KIAS}$ with the flaps set at $40^{\circ}$. Power levers were gradually advanced and pitch attitude adjusted to maintain speed. Elevator control force and pitch characteristics were evaluated throughout the maneuver. 
Pushover maneuvers (Figure 7-Figure 8) described in this report were flown with the Failed Boot ice shape, and flaps set at $20^{\circ}$. Pilots were asked to perform the maneuvers from an initial level flight trimmed condition at 75 KIAS. A shallow dive was then entered to approximately $100 \mathrm{KIAS}$ at which point the pilot would initiate a $1.5 \mathrm{G}$ pull-up. At approximately 15 knots above trim speed, the pilot would begin the pushover, using either a slow constant push on the elevator, or a step input technique. The objective of the task was to achieve a zero-G condition as the aircraft passed through the level flight attitude at trim speed. Control Force Reversal (CFR) was then qualitatively assessed by tactile feedback in the elevator control column. Post flight data analysis of elevator deflection angle $(\delta \mathrm{E})$ and stick force (FYE) provided verification to the pilot comments.

Repeat Elevator Doublet maneuvers (Figure 9-Figure 10) were flown with the Failed Boot ice shape with flaps at $20^{\circ}$ and $30^{\circ}$. The aircraft was initially trimmed for level flight at 75 KIAS. A sharp series of repeat elevator doublets, each held for approximately one second, were input by the pilot. Pitch response and damping characteristics were observed throughout the maneuver, along with tactile feedback in the control column. Damped or divergent response was assessed as the criteria for acceptable flying qualities.

Simulated approach and go-around maneuvers (Figure 11-Figure 14) were flown to assess the effects of tailplane contamination on the performance of this task. The task was flown "heads down", at altitude, with the Failed Boot ice shape and flaps set to both $\delta F=20^{\circ}$ and $30^{\circ}$. During the maneuver, the Flight Test Engineer commanded course and glide slope corrections, forcing the pilot to change both rate of descent (ROD) and heading every 20 seconds, while maintaining a constant $1.3 \mathrm{Vs}$ velocity. Heading changes of $\pm 5^{\circ}$ off a reference heading, and RODs of 0,500 , or $1000 \mathrm{ft} / \mathrm{min}$ were commanded. Pilots were required to maintain ROD's within $\pm 100 \mathrm{ft} / \mathrm{min}$ of target. The idealized flight paths are represented by the dashed lines in Figure 11 through Figure 14. The $20 \mathrm{sec}$ intervals required the pilot to make fairly aggressive control and thrust inputs. At the conclusion of the simulated approach, a go-around was commanded requiring takeoff thrust while raising the nose to maintain airspeed. After the pilot established a positive rate of climb, the flaps were raised. Upon completion of the maneuver, the pilot rated both the approach and go-around task, using the Cooper-Harper handling qualities rating scale (Figure 15).

\section{RESULTS AND DISCUSSION}

The results and discussions that follow are referenced to specific test points conducted during the course of the program. Figures of Flap Transitions, Constant Airspeed
Thrust Transitions, and Repeat Elevator Doublets were from NASA tests only. The results of the zero-G Pushovers and Approach and Go-Around were from tests with both NASA and guest pilot as participants. The following discussions are comments and perspectives from the pilots who participated in each respective test.

Flap Transitions: Referring to Figure 4, the flap transition flown with a baseline (un-iced) tail demonstrates typical longitudinal statically stable characteristics. As flap angle increased, elevator push force (Yoke Force in chart) increased to about $30 \mathrm{lbs}$. as the flaps moved from $\delta F=0$ $10^{\circ}$. As the flaps moved $\mathrm{dF}=10-40^{\circ}$, the elevator push force decreased to about $10 \mathrm{lbs}$., but always remained a push force. However, with the failed boot ice shape, Figure 5 , the elevator force reversed from a peak push force of about $30 \mathrm{lbs}$. at $\delta F=7^{\circ}$, to a pull of about $30 \mathrm{lbs}$. at $\delta F=40^{\circ}$. This force feedback to the pilot is indicative of a large change in hinge moment, due to the change in pressure distribution on the underside of the elevator. As the wing flaps reached $35^{\circ}$, the elevator began a pulsing motion, which the pilot could not arrest. Pilot elevator forces were also oscillatory. Videos of tufts on the underside of the tailplane confirmed the presence of an unsteady separation bubble that covered approximately $25 \%$ of the chord from the leading edge. Level flight in this configuration was maintainable, but the pulsation in the control column made precise attitude control very difficult, and longitudinal trim was not possible. In addition, there was a strong non-linear elevator control force gradient, which resulted in high pull forces when making nose-up corrections and a strong negative pitchover tendency when correcting towards nose-down. With full flaps $\left(\delta \mathrm{F}=40^{\circ}\right)$, longitudinal handling qualities for maintaining a level flight task were not acceptable.

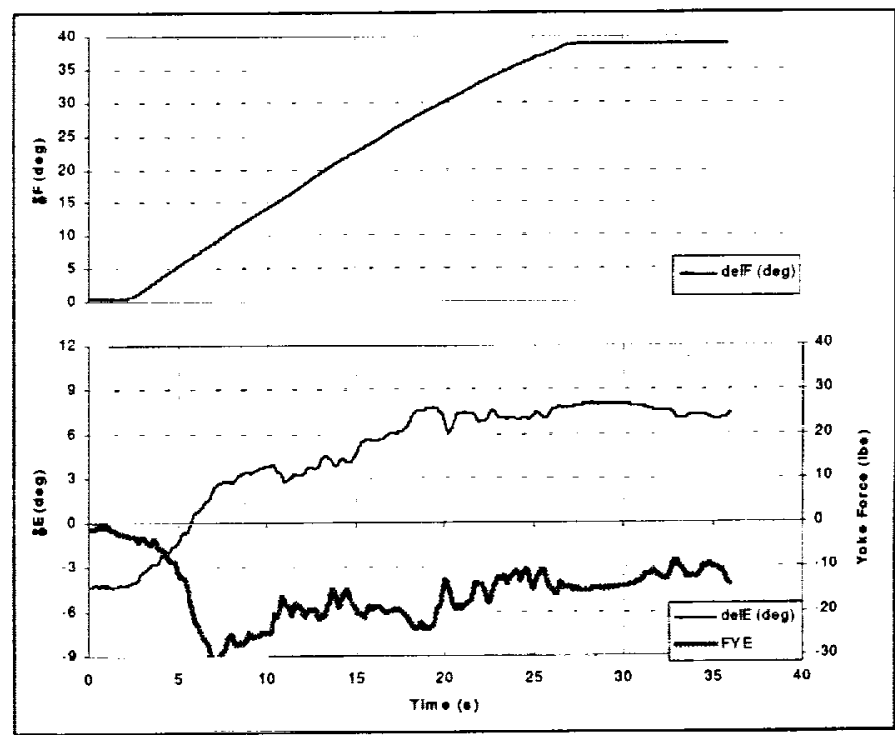

Figure 4. Flap transition - baseline, $V=85 \mathrm{KIAS}$ 


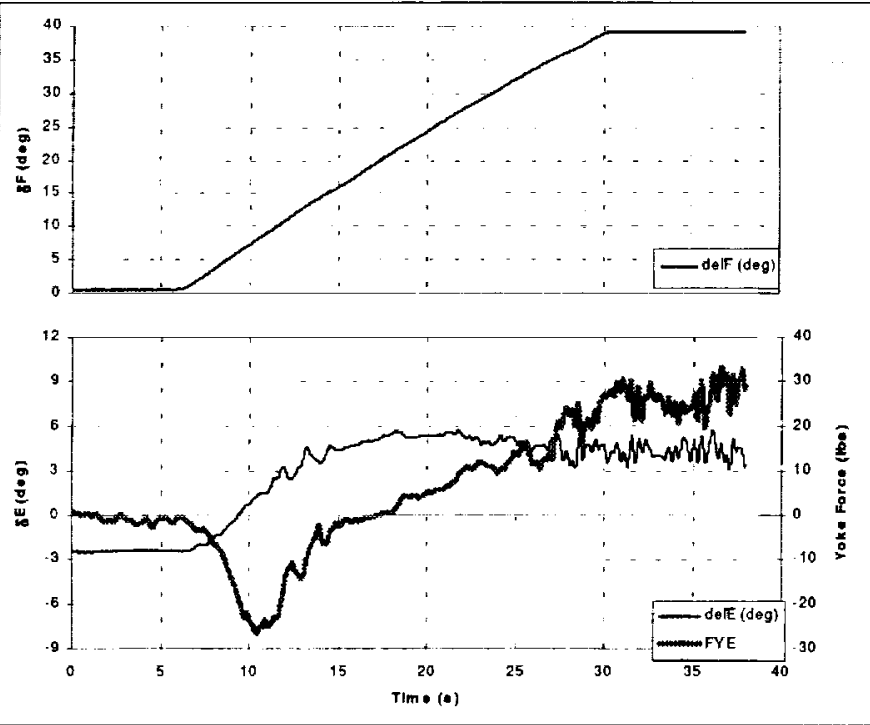

Figure 5. Flap transition - Failed Boot Ice, V=95KIAS

Constant Airspeed Thrust Transition: The constant airspeed thrust transition provided one of the more surprising results of the test program. Referring to Figure 6 , pilot elevator force (FYE in chart) increased as thrust was applied. Throughout the thrust application, the Flight Test Engineer reported a growth in the separation bubble as seen from the video of the tufts on the underside of the tailplane. Elevator pulsing became severe, and pitch control became increasingly more difficult to maintain. Approaching moderate thrust, elevator force rapidly built to approximately $100 \mathrm{lbs}$., followed by a hard negative pitch rate as the horizontal tail stalled. Aft control column was immediately applied, and elevator force reached about $170 \mathrm{lbs}$. Thrust was simultaneously reduced to idle, and the flaps raised to break the stall. The aircraft was recovered from an approximate $40^{\circ}$ nose-down attitude, and returned to level flight. This maneuver demonstrated the effects of thrust on tailplane lift characteristics. Since the thrust line of this aircraft is above the center of gravity, increased thrust caused a nose-down pitching moment, which further increased the trimmed lift requirements of the horizontal tailplane. The ice shape reduced the tail lift capability to the point where a stall ensued as elevator was applied to trim off the effect of increased engine thrust.

Pushover Maneuvers: Zero-G pushover maneuvers are flown to identify elevator Control Force Reversal (CFR) characteristics with an ice-contaminated tailplane. The certification criteria at zero-G requires that no CFR occur, and that the aircraft return to trimmed flight upon release of the elevator during the maneuver. This is an important test, which if failed, can result in the imposition of reduced flap angles for approach and landing, decreasing landing performance. Zero-G maneuvers were therefore flown in the TIP Guest Pilot Program for two purposes: 1.) They offered test pilots the opportunity to compare their subjective evaluation of CFR against

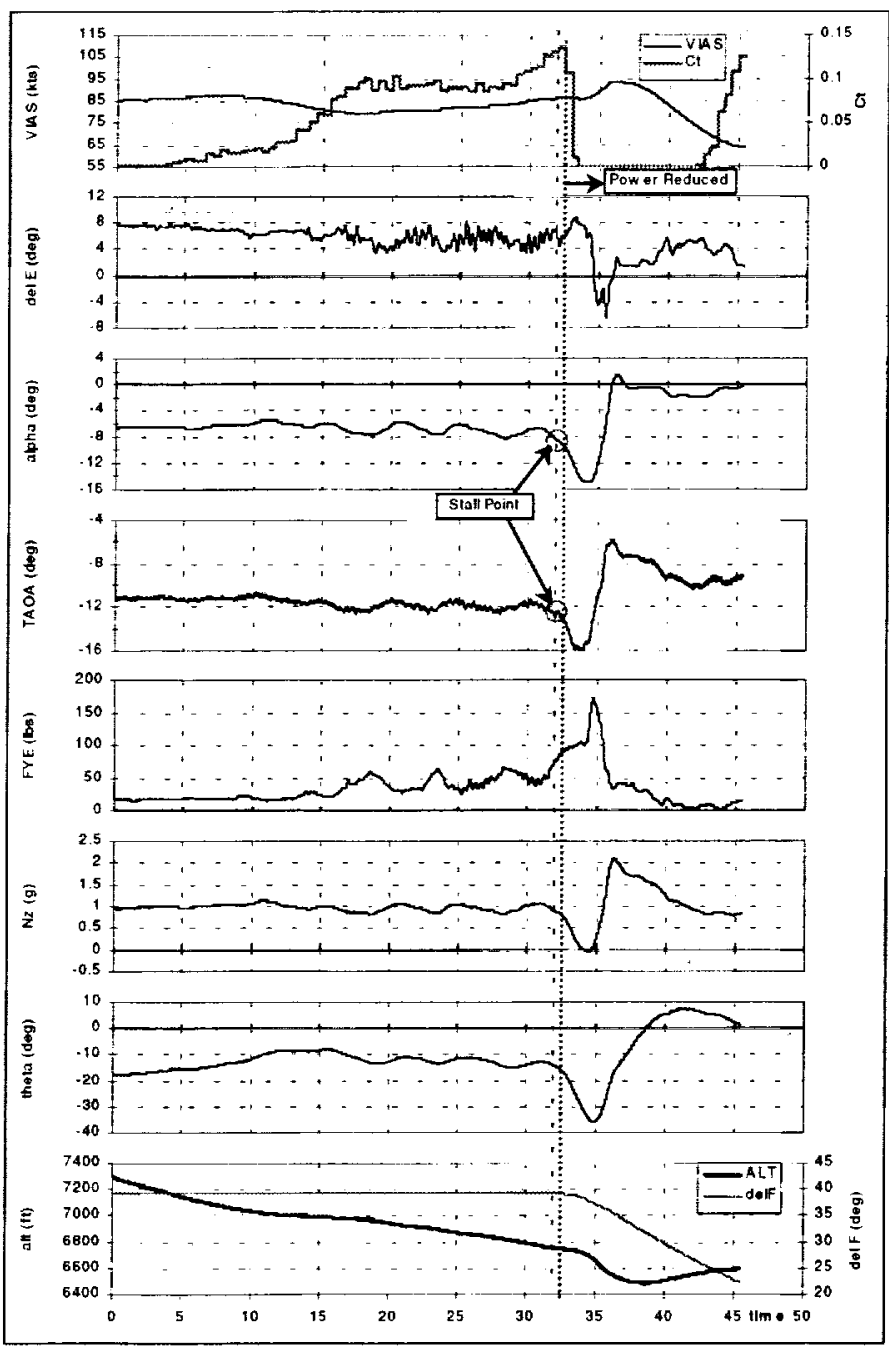

Figure 6. Thrust transition - Failed Boot ice, $\delta \mathrm{F}=40^{\circ}$

different control techniques; and 2.) Test pilots could compare the zero-G pass/fail criteria against a taskoriented flying qualities evaluation in the same configuration. The following discussion will focus on results obtained in the first case. The second case will be discussed with the results of the task-oriented maneuver. For some tests, the CFR or no CFR assessment can be strictly a judgement call on the part of the test pilot. Figure 7 \& Figure 8 show the results of two widely different techniques in performing the zero-G pushover maneuver. Figure 7 is the result of a slow smooth pushover, while Figure 8 is the result of an aggressive step function input. The target speed at the zero-G condition in both cases was $75 \mathrm{KIAS}$. It is apparent that CFR occurred in both cases, i.e., the control force (Stick Force in chart) crossed the trim point before the elevator was deflected trailing edge up. Moreover, the onset of CFR occurred at approximately the same G-level, regardless of technique. Pilots flying the maneuvers, however, indicated that they could do a better job in detecting the onset of CFR approaching the zero-G condition using the slower, more gradual entry, than the more aggressive step function. Pilots indicated that tactile feedback assessments over the relatively short 
two-second interval experienced during the step inputs were harder to accurately sense than the feedback experienced over the slower, $5 \mathrm{sec}$ entry. This result may be indicative of the need to ensure that qualitative assessments of CFR require a consistent technique on the part of test pilots performing the evaluation. Where data systems are used to record the required parameters, pilot technique is of lesser importance.

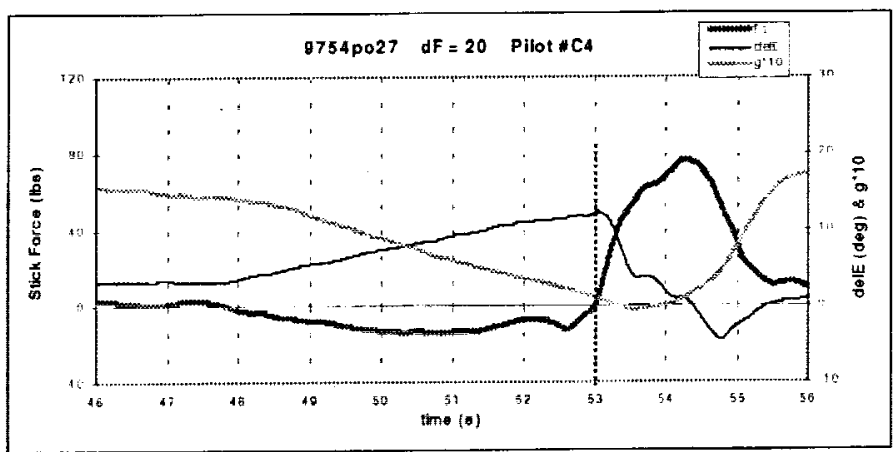

Figure 7. Zero-G pushover- Failed Boot ice, slow input, $\delta F=20^{\circ}$

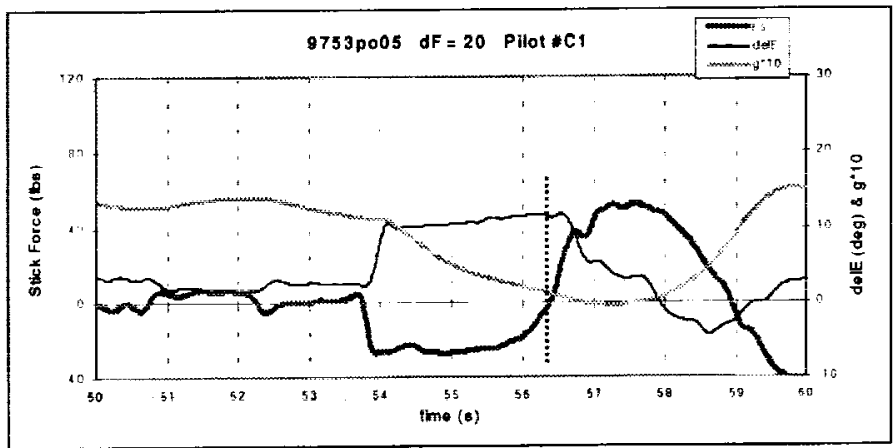

Figure 8. Zero-G pushover - Failed Boot ice, step input, $\delta \mathrm{F}=20^{\circ}$

Elevator Doublets: Elevator doublets provided a means for comparing pitch response characteristics of the Twin Otter between a clean and an ice-contaminated tailplane (ICT). A damped response indicated dynamic longitudinal stability, and an undamped response indicated divergence. In the undamped case, controllability was apparent if the aircraft responded in the proper sense to elevator input. Poor or no pitch damping makes the aircraft difficult to control precisely. When performing a pitching maneuver, pitch damping lends a measure of predictability to the piloting task, and in turn, has a large bearing on the pilot's impression of the aircraft's flying qualities. To illustrate, Figure 9 compares pitch response characteristics between a clean and ICT condition with flaps set at $30^{\circ}$. Note: The ICT condition in this particular example was a special artificial shape (S\&C ice) that provided a more degraded stability and control characteristic than the Failed Boot case. The purpose for introducing this configuration here is to clearly illustrate the difference between damped and undamped characteristics. In both the clean and S\&C ice cases, a repeat pitch doublet was applied within a 10-second interval. In the clean case, note that the aircraft response was damped within approximately 0.5 second of the initial input for each interval flown. However, in the ICT case, the response remained divergent until the pilot applied an opposite elevator input. With ICT, aircraft was dynamically unstable, but controllable. In this condition, the aircraft could be safely flown, providing that control inputs were very small, and resulted in relatively low vertical acceleration rates. The data shown here resulted in vertical acceleration rates on the order of $+/-0.5 \mathrm{G}$.

This test technique was also applied to cases where the tail was configured with the Failed Boot condition. In Figure 10 , repeat doublets for the $30^{\circ}$ flap setting show that the pitch response was undamped, but damped with flaps at $20^{\circ}$. From a flying qualities standpoint, the aircraft was stable and controllable with flaps set at $30^{\circ}$, at low thrust settings, providing that pitch rates did not introduce vertical accelerations exceeding $+/-0.25 \mathrm{G}$. On the other hand, with flaps at $20^{\circ}$, the aircraft was stable and controllable at all thrust settings provided that pitch rates did not introduce vertical accelerations exceeding $+/-0.5 G$. Therefore, the elevator doublet maneuver is an effective means of assessing stability and controllability, and correlates with pilot handling assessments of the approach task described in the next section of this report.

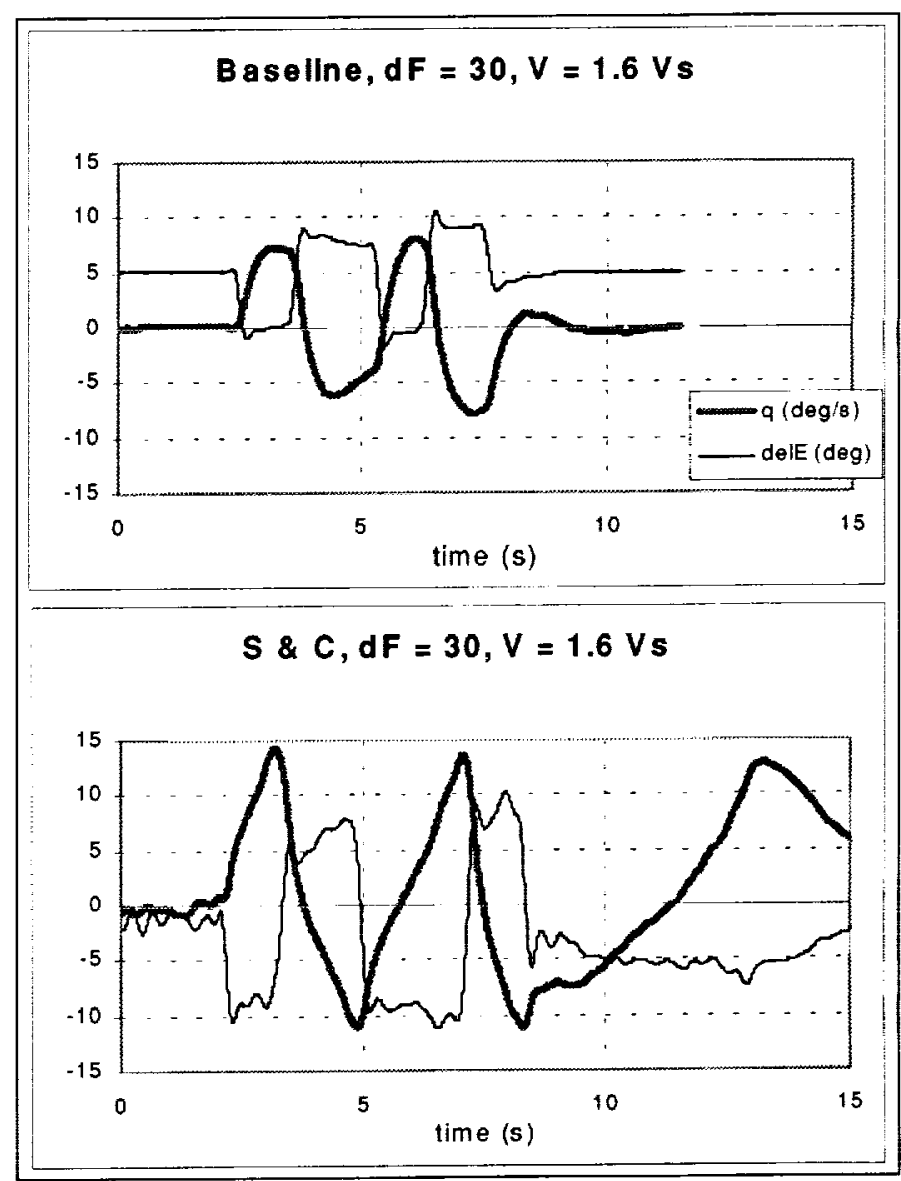

Figure 9. Elevator doublet comparison - S\&C Ice 

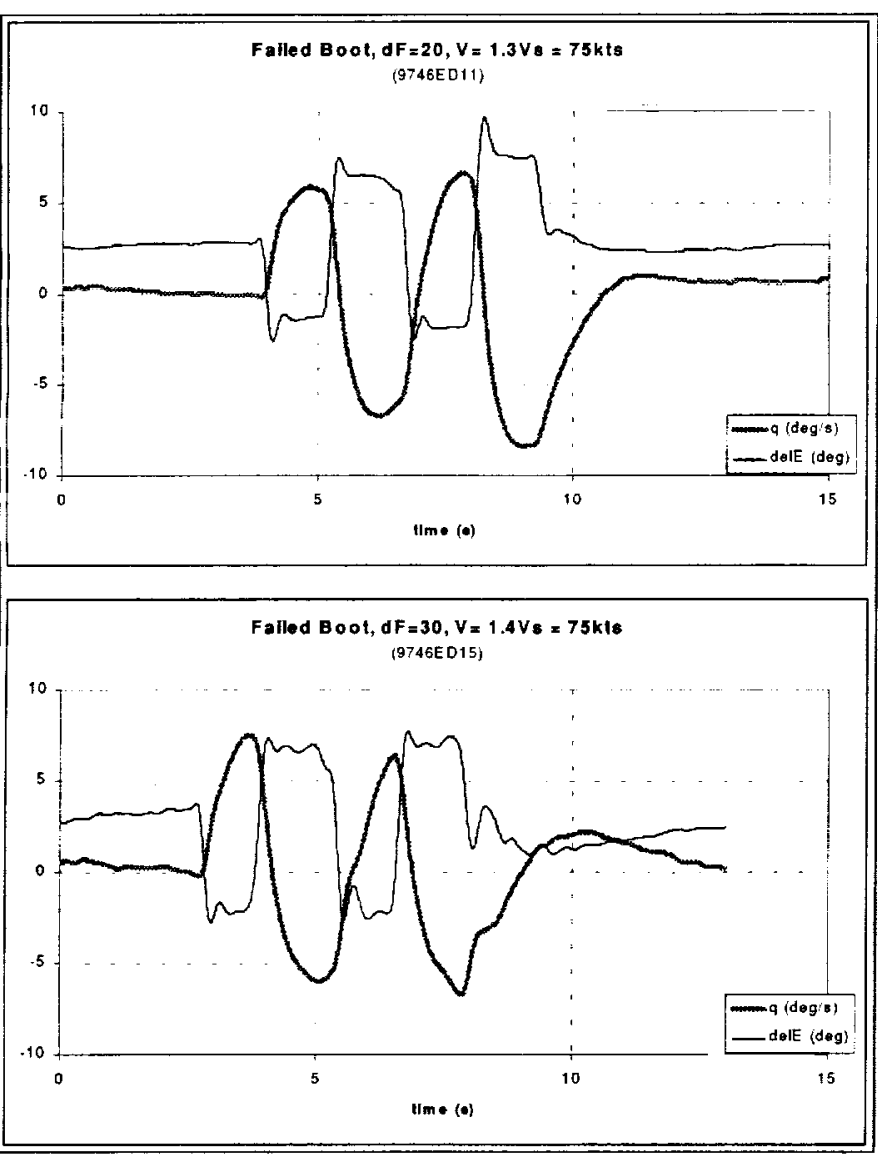

Figure 10. Elevator doublet comparison - Failed Boot

\section{Handling Assessment of an Approach and Go-Around}

Task:

Five pilots representing industry and NASA were asked to evaluate the approach and go-around landing tasks for flap settings of $20^{\circ}$ and $30^{\circ}$ with the Failed Boot ice shape. The Cooper-Harper (C-H) rating scale (Figure 15) was used as the rating criteria. Handling Quality Ratings (HQR) were assessed to determine flying qualities for both the approach and go around tasks. Based on these ratings, the configuration tested was assessed as having either Level I (minor deficiencies and no improvements required), Level II (deficiencies require improvement), or Level III (deficiencies require mandatory improvement) flying qualities.

The performance and tracking accuracy for two representative pilots are shown relative to the flap configuration and task segment in Figure 11- Figure 14. The dashed line in these figures represents the commanded change in either descent rate or heading, and provides no adjustment for pilot reaction time. Pilots were asked to be as aggressive as possible in responding to commands. Figure 11 and Figure 12 display results from the $20^{\circ}$ flap cases. Handling quality ratings (HQR) from each pilot are summarized in Figure 16 for the given portion of the task flown. With flaps set at $20^{\circ}$, descent and heading tracking was readily accomplished during the approach phase, and all pilots rated the airplane Level I, meaning that the task could be performed with minimal pilot compensation. This rating correlated with the results of the repeat elevator doublets (Figure 10-upper), which showed that in this configuration, the airplane was stable, controllable, and that response to elevator input was well damped. Note that during the elevator doublets, G-levels were approximately $+/-0.5 \mathrm{G}$, and thrust was set at $C_{T}=0.11$, which was approximately the same $C_{T}$ used for the level flight portion of the simulated approach task. The goaround task, however required thrust settings of approximately $\mathrm{C}_{\mathrm{T}}=0.24$. This configuration and thrust setting induced power effects that reduced flying qualities to Level II. In summary, three pilots rated the go-around task as having mildly unpleasant deficiencies, one rated it as having minor but annoying deficiencies, and one rated it as having very objectionable deficiencies. Here pilot ratings indicated that minimal to extensive compensation was required to achieve the desired performance, although stability and controllability were never in question.

The same approach and go-around tasks were then flown with flaps set to $30^{\circ}$. Figure 13 and Figure 14 display pilot performance in the $30^{\circ}$ flap cases. Four pilots rated the airplane Level II, i.e. HQR's from 3 through 6 , while one rated it a Level III with a HQR of 8 . Pilots who felt that the airplane fell within Level II criteria seemed to agree that control buffet was quite evident, precise tracking was difficult, and required pilot compensation was moderate to extensive. The pilot who provided an HQR of 8 (Level III) appeared to have reached task saturation while performing the maneuver. Comparing these results to the elevator doublets in the $30^{\circ}$ flap configuration, (Figure 10-bottom), we note that the aircraft displayed weak or no damping in response to elevator inputs. In this case, it is evident that HQR's do reflect the poor stability and control characteristics shown in the doublet maneuvers. Again, $G$ levels reached in the doublet maneuvers were $+/-0.5 \mathrm{G}$. All pilots rated the airplane a Level III while performing the go-around maneuver with flaps set to $30^{2}$. Here, the addition of maximum thrust severely degraded elevator authority as pilots struggled to execute a precise pitch tracking task. Pilot comments indicated that the maneuver was very difficult to perform, elevator buffet was excessive, intense compensation was required, and one pilot felt he could not control the airplane at all. 


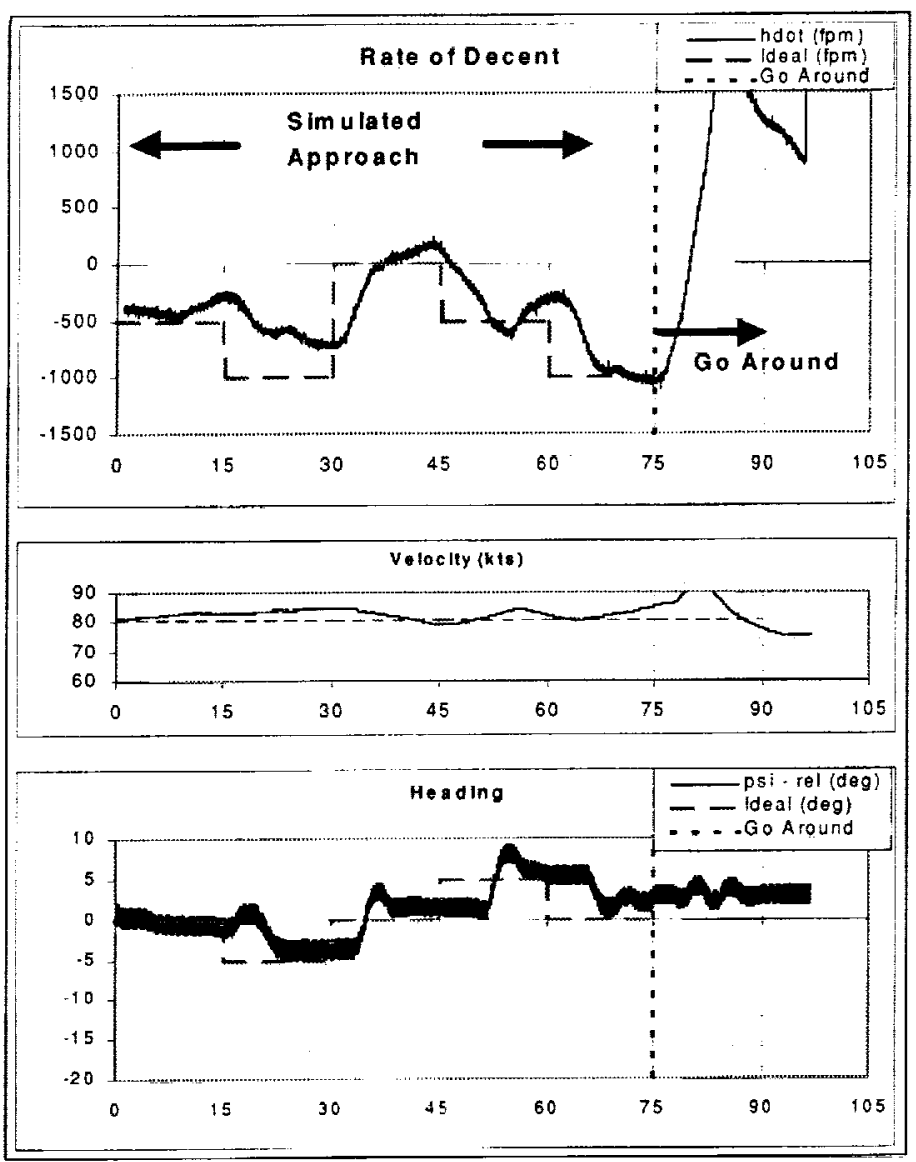

Figure 11. Approach \& Go-around, $\delta F=20^{\circ}$, pilot 1

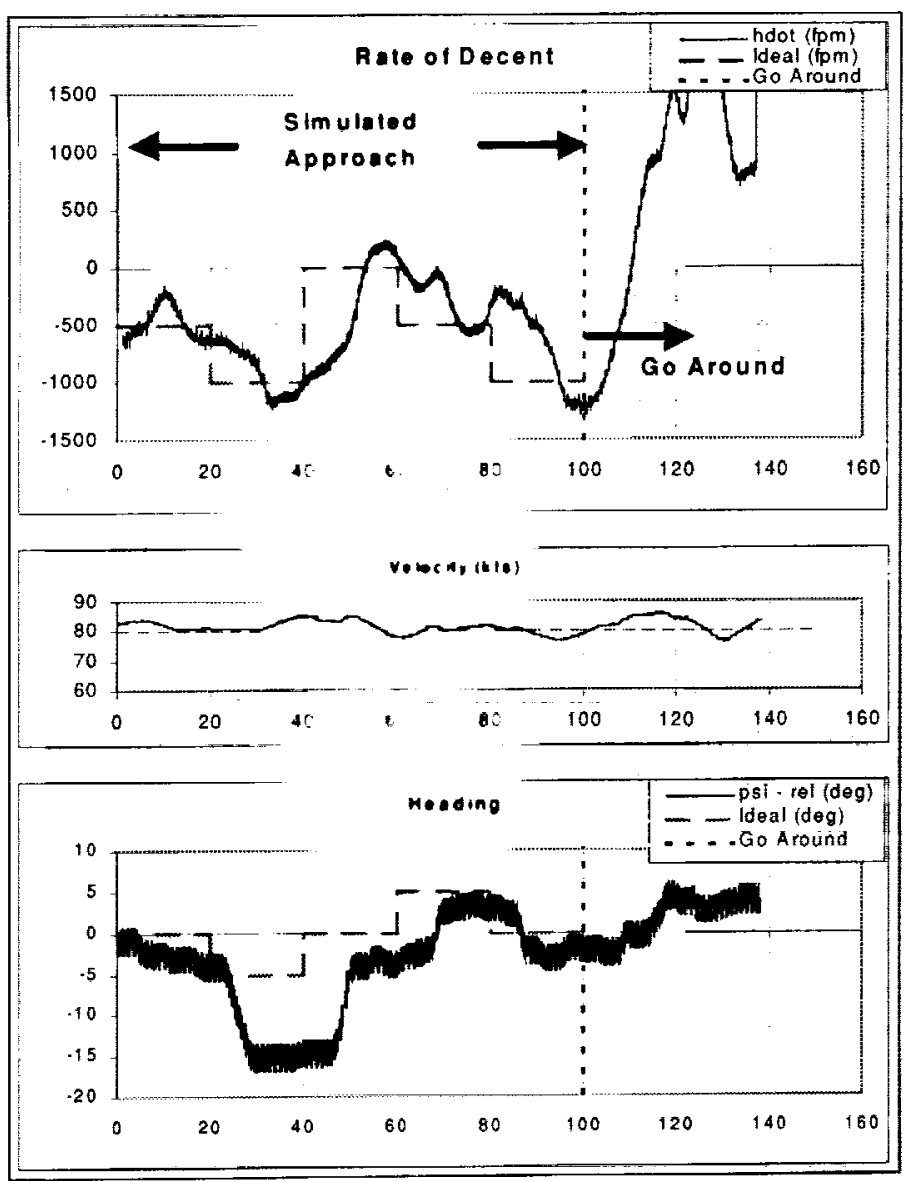

Figure 12. Approach \& Go-around, $\delta F=20^{\circ}$, pilot 3

NASA/TM-2000-210356

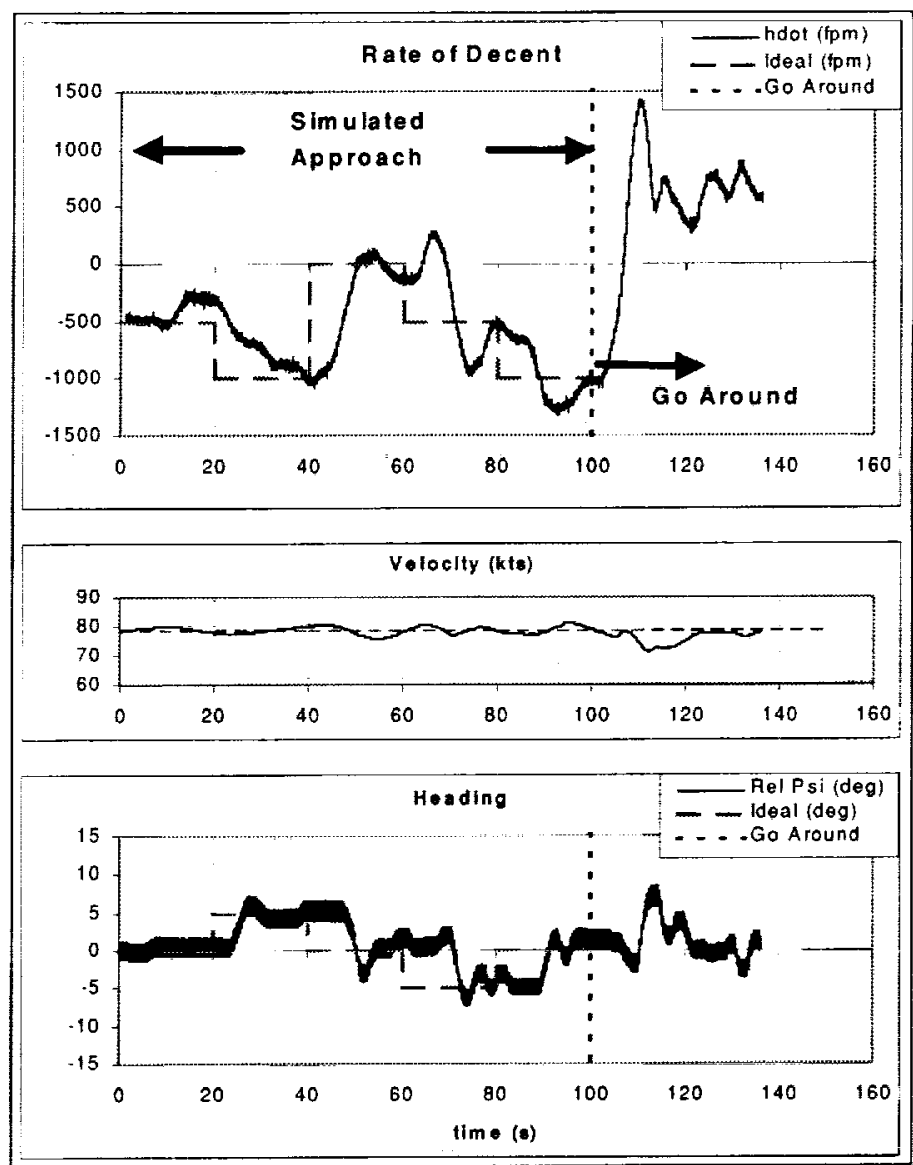

Figure 13. Approach \& Go-around, $\delta \mathrm{F}=30^{\circ}$, pilot 1

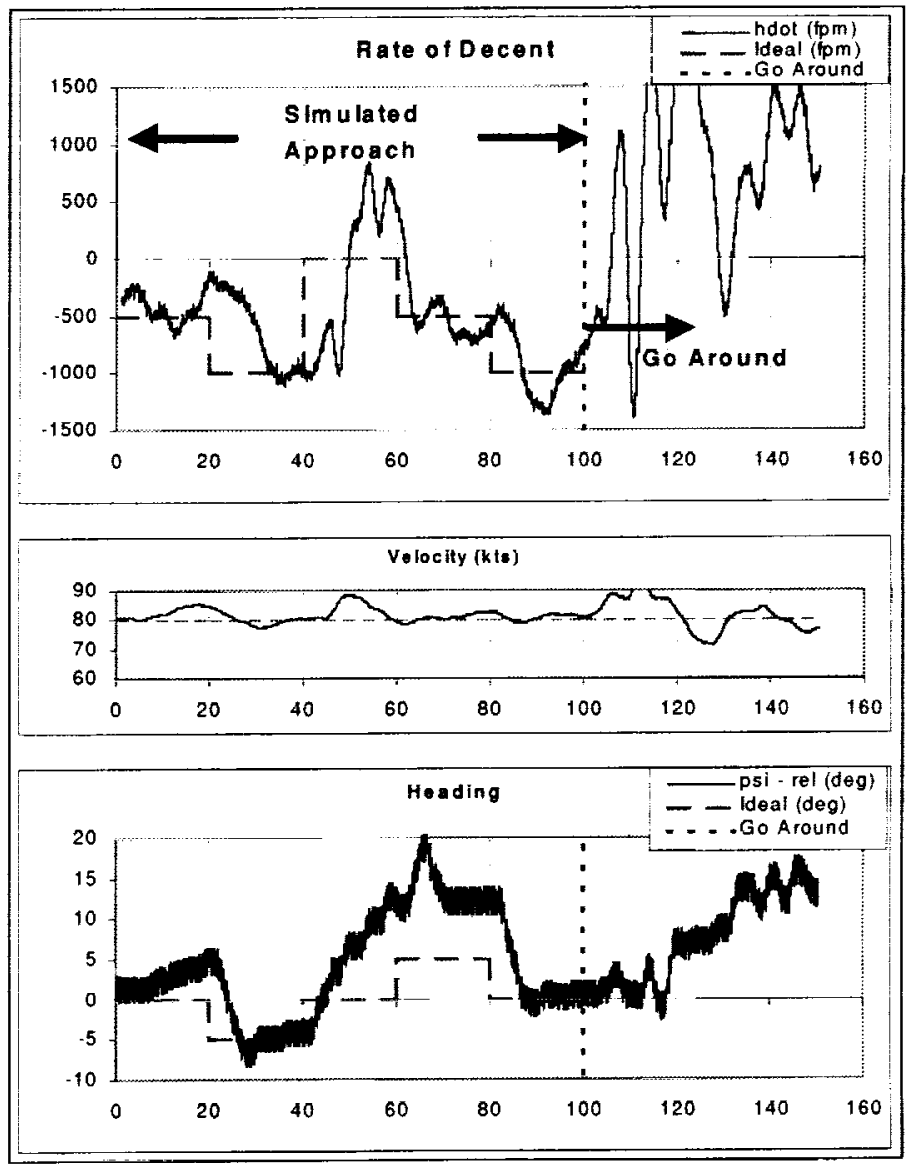

Figure 14. Approach \& Go-around, $\delta F=30^{\circ}$, pilot 3 


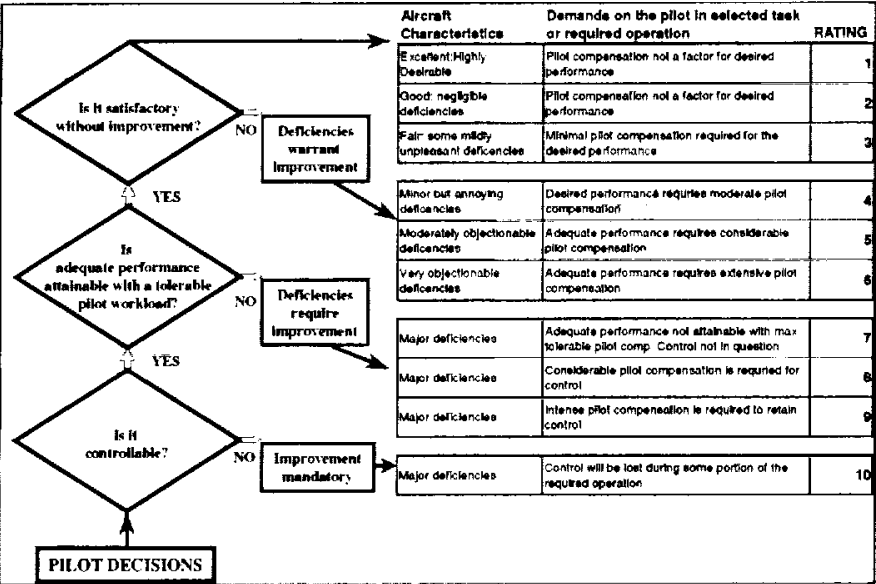

Figure 15. Cooper-Harper HQ Rating Flow Chart

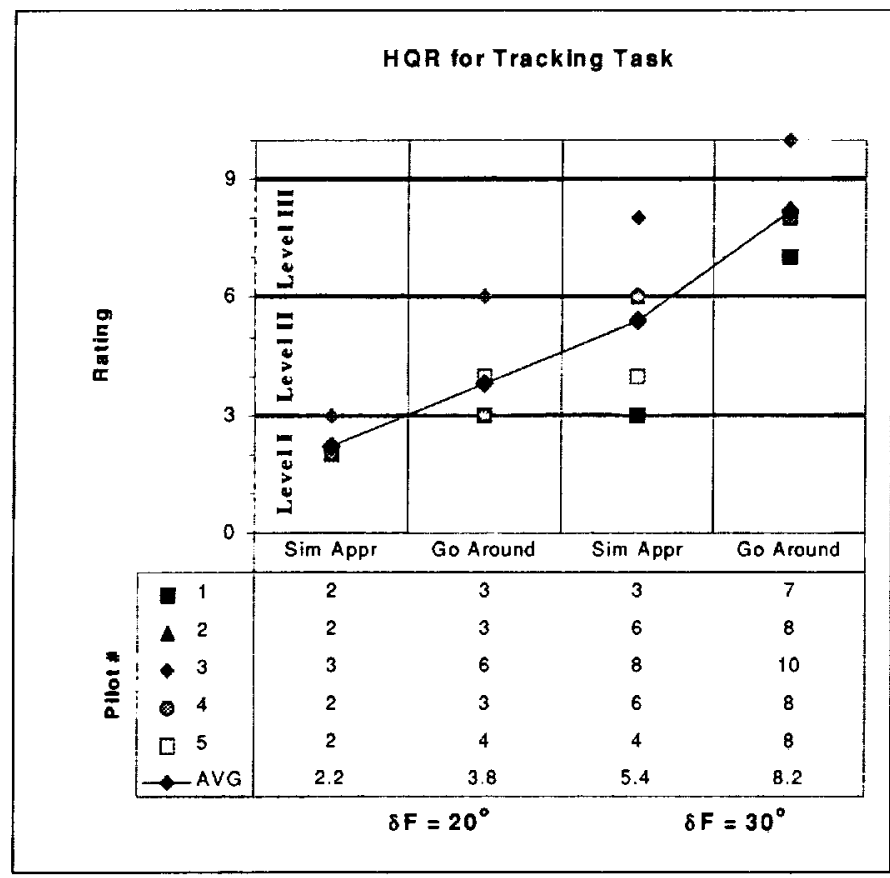

Figure 16. HQR for Approach and Go-Around Tasks

\section{CONCLUSION}

The NASA Twin Otter Icing Research Aircraft provided an excellent test vehicle for investigating the effects of tailplane icing on longitudinal flying qualities. Artificial ice shapes used on the tailplane caused a progressive reduction in longitudinal static stability as wing flaps were lowered, a characteristic which was manifested by inability to trim, and a tendency to diverge from a desired flight path following an elevator input. The condition was also accompanied by a pulsing of the control column, which was the result of a highly unsteady separation bubble on the underside of the tail that grew as a function of increasing flap angle. Aggressive pilot elevator inputs, such as those used in performing repeat elevator doublets, would further aggravate the unsteadiness of the condition, and result in longitudinally unstable dynamic responses. These responses were relatively easy to control. They provided a good means for assessing acceptable flying characteristics, based on pitch damping and control effectiveness. The zero-G maneuvers, however, were more difficult to perform consistently. Pilot comments supported the fact that tactile cues for CFR could be masked to a degree by pilot technique, however the data showed that pilot technique was not a factor on a CFR. Using a properly structured task-oriented methodology, which in this case was an approach and go-around task, an accurate assessment of adequate flying qualities was made. In the $20^{\circ}$ flap cases where pitch response was well damped, pilot task ratings showed that the aircraft met Level I flying qualities criteria. When performing the more severe go-around maneuver, the aircraft still met Level II criteria. However, the same configuration did not pass the noCFR requirement when a zero-G pushover was performed. Although the zero-G pushover maneuver may provide a rather conservative screening test for ICTS, the potential restrictions it imposes on the aircraft flight envelope can be excessive.

\section{REFERENCES}

1. Dow, J.P. Sr., FAA Small Airplane Directorate, private communication

2. NASA/FAA Tailplane Icing Program Overview, T.P. Ratvasky, J.F. Van Zante, J.T. Riley, NASA TM-1999208901, AIAA-99-0370, Jan, 1999

3. DHC-6 Twin Otter Tailplane Airfoil Section Testing in the Ohio State University 7'X10' Wind Tunnel. D.W. Hiltner, M. McKee, K.B. La Noé, G. Gregorek, NASA CR-209921 Vol. 1, publishing pending

4. Additional Testing of the DHC-6 Twin Otter lced Airfoil Section at the Ohio State University $7^{\prime} \times 10^{\prime}$ Low Speed Wind Tunnel. G. Gregorek, J. Dreese, K.B. La Noé, NASA CR-209921 Vol. 2, publishing pending

5. NASA/FAA Tailplane Icing Program: Flight Test Report. T.P. Ratvasky, J.F. Van Zante, A. Sim, NASA TP-209908, DOT/FAA/AR-99/85, March, 2000

6. Investigation of Dynamic Flight Maneuvers With an Iced Tailplane, J.F. Van Zante, T.P. Ratvasky, NASA TM208849, AIAA-99-0371, Jan. 1999

7. In-Flight Aerodynamic Measurements of an lced Horizontal Tailplane, T.P. Ratvasky, J.F. Van Zante, NASA TM-208902, AIAA-99-0638, Jan. 1999

8. A Nonlinear Aircraft Simulation of lce Contaminated Tailplane Stall. D.W. Hiltner, Ph.D. Dissertation, 1998

9. An Evaluation of an Analytical Simulation of an Airplane with Tailplane Icing by Comparison to Flight Data. D.W. Hiltner, NASA CR, publishing pending.

10. Tailplane Icing. NASA Glenn Research Center, video tape, 1998. http://icebox.lerc.nasa.gov/Education/Videos/

11. Icing for Regional and Corporate Pilots. NASA Glenn Research Center, video tape, 1999. http://icebox.lerc.nasa.gov/Education/Videos/

12. Learjet Syllabus and Background Material for the U.S. Air Force/ U.S. Navy Test Pilot School Programs. J. Ball, C. Berthe, S. Buethe, L. Knotts, M. Parrag, Feb 1994 
Public reporting burden for this collection of information is estimated to average 1 hour per response, including the time for revtewing instructions, searching existing data sources, gathering and maintaining the data needed, and completing and reviewing the collection of information. Send comments regarding this burden estimate or any other aspect of this gatetion of intormation including suggestions for reducing this burden, to Washington Headquarters Services, Directorate for Information Operations and Feports, 1215 Jefferson Davis Highway, Suite 1204, Arlington, VA 22202-4302, and to the Otfice of Management and Budget, Paperwork Reduction Prolect (0704-0188), Washington, DC 20503.

\begin{tabular}{l|l|l}
\hline 1. AGENCY USE ONLY (Leave blank) & 2. REPORT DATE & 3. REPORT TYPE AND DATES COVERED
\end{tabular}

4. TITLE AND SUBTITLE

September 2000

Technical Memorandum

Flying Qualities Evaluation of a Commuter Aircraft With an Ice

Contaminated Tailplane

6. AUTHOR(S)

WU-548-2I-23-00

Richard J. Ranaudo, Thomas P. Ratvasky, and Judith Foss Van Zante

7. PERFORMING ORGANIZATION NAME(S) AND ADDRESS(ES)

National Aeronautics and Space Administration

John H. Glenn Research Center at Lewis Field

Cleveland, Ohio 44135-3191

5. FUNDING NUMBERS

9. SPONSORING/MONITORING AGENCY NAME(S) AND ADDRESS(ES)

National Aeronautics and Space Administration

Washington, DC 20546-0001

8. PERFORMING ORGANIZATION REPORT NUMBER

E-12405

10. SPONSORING/MONITORING AGENCY REPORT NUMBER

NASA TM-2000-210356

SAE 2000-01-1676

11. SUPPLEMENTARY NOTES

Prepared for the General Aviation Technology Conference and Exposition (GATC) sponsored by the Society of

Automotive Engineers, Wichita, Kansas, May 9-11, 2000. Richard J. Ranaudo, Bombardier Aerospace, 1 Learjet Way,

Wichita, Kansas 67277; Thomas P. Ratvasky, NASA Glenn Research Center; Judith Foss Van Zante, Dynacs Engineering

Company, Inc., 2001 Aerospace Parkway, Brook Park, Ohio 44142. Responsible person, Thomas P. Ratvasky, organization code 5840 ,

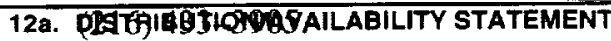

12b. DISTRIBUTION CODE

Unclassified - Unlimited

Subject Categories: 08, 05 and 02

Distribution: Nonstandard

This publication is available from the NASA Center for AeroSpace Information, (301) 621 0390 .

13. ABSTRACT (Maximum 200 words)

During the NASA/FAA Tailplane Icing Program, pilot evaluations of aircraft flying qualities were conducted with various ice shapes attached to the horizontal tailplane of the NASA Twin Otter Icing Research Aircraft. Initially, only NASA pilots conducted these evaluations, assessing the differences in longitudinal flight characteristics between the baseline or clean aircraft, and the aircraft configured with an Ice Contaminated Tailplane (ICT). Longitudinal tests included Constant Airspeed Flap Transitions, Constant Airspeed Thrust Transitions, zero-G Pushovers, Repeat Elevator Doublets, and, Simulated Approach and Go-Around tasks. Later in the program, guest pilots from govemment and industry were invited to fly the NASA Twin Otter configured with a single full-span artificial ice shape attached to the leading edge of the horizontal tailplane. This shape represented ice formed due to a "Failed Boot" condition, and was generated from tests in the Glenn Icing Research Tunnel on a full-scale tailplane model. Guest pilots performed longitudinal handling tests, similar to those conducted by the NASA pilots, to evaluate the ICT condition. In general, all pilots agreed that longitudinal flying qualities were degraded as flaps were lowered, and further degraded at high thrust settings. Repeat elevator doublets demonstrated reduced pitch damping effects due to ICT, which is a characteristic that results in degraded flying qualities. Pilots identified elevator control force reversals (CFR) in zero-G pushovers at a $20^{\circ}$ flap setting. a characteristic that fails the FAR 25 no CFR certification requirement. However, when the same pilots used the Cooper-Harper rating scale to perform a simulated approach and go-around task at the $20^{\circ}$ flap setting, they rated the airplane as having Level I and Level II flying qualities respectively. By comparison, the same task conducted at the $30^{\circ}$ flap setting, resulted in Level II flying qualities for the approach portion, and Level III for the go-around portion. The results of this program indicate that safe and acceptable flying qualities with an ICT condition, can be effectively assessed by task-oriented pilot maneuvers. In addition, other maneuvers such as repeat elevator doublets provide good qualitative and quantitative assessments of pitch damping and elevator effectiveness, which are characteristics that correlate well with pilot task ratings. The results of this testing indicate that the FAR 25 zero-G pushover maneuver, which requires no CFR during its execution, may be an overly conservative pass/fail criteria for aircraft certification.

\begin{tabular}{l|l} 
14. SUBJECT TERMS & 15. NUMBER OF PAGES
\end{tabular}

Aircraft icing; Tailplane icing; Stability and control; Flying qualities

\begin{tabular}{|c|c|c|}
\hline $\begin{array}{c}\text { 17. SECURITY CLASSIFICATION } \\
\text { OF REPORT } \\
\text { Unclassified }\end{array}$ & $\begin{array}{c}\text { 18. SECURITY CLASSIFICATION } \\
\text { OF THIS PAGE } \\
\text { Unclassified }\end{array}$ & $\begin{array}{c}\text { 19. SECURITY CLASSIFICATION } \\
\text { OF ABSTRACT } \\
\text { Unclassified }\end{array}$ \\
\hline
\end{tabular}

NSN 7540-01-280-5500

Unclassified
15

16. PRICE CODE

$\mathrm{AO} 3$

20. LIMITATION OF ABSTRACT

Standard Form 298 (Rev. 2-89)

Prescribed by ANSI Std. Z39-18 298-102 